\title{
Hydrostatic Pressure-Induced Spectral Variation of Reichardt's Dye: A Polarity/Pressure Dual Indicator
}

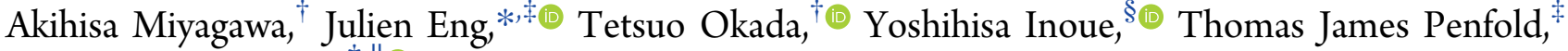 \\ and Gaku Fukuhara*, ${ }^{\dagger}, \|_{\infty}$ \\ ${ }^{\dagger}$ Department of Chemistry, Tokyo Institute of Technology, 2-12-1 Ookayama, Meguro-ku, Tokyo 152-8551, Japan \\ ${ }^{\ddagger}$ Chemistry- School of Natural and Environmental Sciences, Newcastle University, Newcastle upon Tyne NE1 7RU, U.K. \\ ${ }^{\S}$ Department of Applied Chemistry, Osaka University, 2-1 Yamada-oka, Suita 565-0871, Japan \\ "JST, PRESTO, 4-1-8 Honcho, Kawaguchi, Saitama 332-0012, Japan
}

\section{Supporting Information}

ABSTRACT: The famous solvatochromic Reichardt's dye was applied to quantify hydrostatic pressure in media. The UV/vis spectra of the dye in various organic solvents are shifted bathochromically or hypsochromically at the shorter- or longer-wavelength band, respectively, upon hydrostatic pressurization. The $E_{\mathrm{T}}$ value, determined by an absorption maximum, in ethyl acetate increases from $38.5 \mathrm{kcal} \mathrm{mol}^{-1}$ at $0.1 \mathrm{MPa}$ to $39.2 \mathrm{kcal} \mathrm{mol}^{-1}$ at $300 \mathrm{MPa}$, which is mostly equal to the one in chloroform at $0.1 \mathrm{MPa}$. These spectroscopic origins were supported by the time-dependent density functional theory (TD-DFT) calculations. The concept and approach proposed in this paper, i.e., a dual indicator, should attract the attention of a broad spectrum in multidisciplinary science.

\section{INTRODUCTION}

Chemical indicators are a type of sensor that outputs a spectral, optical, or electrochemical signal in response to a chemical input to be quantitatively determined. ${ }^{1}$ For instance, a $\mathrm{pH}$ indicator is a well-known example used to colorimetrically analyze $\mathrm{pH}$ in solution, where proton concentration and UV/ vis spectral changes are the input and output information, respectively. ${ }^{2}$ Such chemical indicators serve as versatile chemosensors for sensing, probing, and imaging a wide range of analytes such as chemicals, ${ }^{3}$ volatile organic compounds (VOC), ${ }^{4}$ explosives, ${ }^{5}$ chiralities, ${ }^{6}$ biomolecules, ${ }^{7}$ and apoptosis for cancer treatments. ${ }^{8}$ Among the many dyes/chromophores/ luminophores reported so far, ${ }^{3-8}$ a colorimetric indicator that can measure media conditions (e.g., polarity, viscosity, and polarizability) is critical for basic science as this makes it possible to more easily elucidate details about solvent-solute interactions. These weak interactions, i.e., solvation, are inherently considered to be one of the entropy-related factors controlling not only supramolecular complexation equilibria in the ground state, ${ }^{9}$ on the basis of eq 1 , but also photoreaction rates in the excited state. ${ }^{10}$

$$
\begin{aligned}
& -R T \ln K=\Delta H^{\circ}-T \Delta S^{\circ} \\
& =\Delta F^{\circ}+P \Delta V^{\circ}
\end{aligned}
$$

Here $K$ represents an equilibrium constant, $R$ is the gas constant, $T$ is the temperature, $P$ is the pressure, $\Delta H^{\circ}$ is the standard enthalpy, $\Delta S^{\circ}$ is the standard entropy, $\Delta F^{\circ}$ is the Helmholtz energy, and $\Delta V^{\circ}$ is the change of volume.

According to eq 2 derived from the common thermodynamic parameters, the pressure term turns out to be a fundamental controllable factor. ${ }^{10 b, 11}$ Indeed, the effect of hydrostatic pressure on molecular recognition in solutions have long been investigated, ${ }^{12}$ and greatly affect volume changes upon complexation. These facts indicate that simultaneously measuring pressure as well as polarity in reaction medium can lead to a deeper mechanistic understanding of the origins controlling chemical reactions. Although various pressureresponsive luminophores in solutions have been developed over the years, ${ }^{13}$ a dual chemometric indicator that is susceptible to mutually related polarity and pressure is quite rare.

Reichardt's dye (1), shown in Figure 1, has long been known as a useful solvatochromic reagent, and generally, an empirical

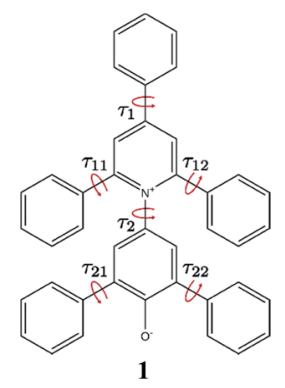

Figure 1. Chemical structure of Reichardt's dye (1) and definitions of the angles $\tau_{i}$.

Received: November 14, 2019

Accepted: December 10, 2019 
$E_{\mathrm{T}}$ value estimated from an absorption maximum in a solvent is now widely employed. ${ }^{14}$ This prompted us to develop a novel dual indicator that exhibits drastic UV/vis spectral changes in response to hydrostatic pressure stimuli as well as solvent polarity.

In the present study, to expand the range of 1 from the original to the dual indicator, we investigated the hydrostatic pressure effects on compound $\mathbf{1}$ in common organic solvents with its spectral variation upon hydrostatic pressurization and also examined the origins of the spectral changes by means of quantum mechanical calculations. The results will be discussed to elucidate the factors governing the hydrostatic pressure outcomes of 1 .

\section{RESULTS AND DISCUSSION}

The hydrostatic pressure effects on the absorption properties of dilute solutions of compound $\mathbf{1}$ were first examined in ethyl acetate, chloroform, dichloromethane, acetone, acetonitrile, 2propanol, ethanol, and methanol as representative eight organic solvents $\left(E_{\mathrm{T}} ; 38.1-55.4 \mathrm{kcal} \mathrm{mol}^{-1}\right)$ using UV/vis spectroscopy. As shown in Figure 2, a broad intramolecular

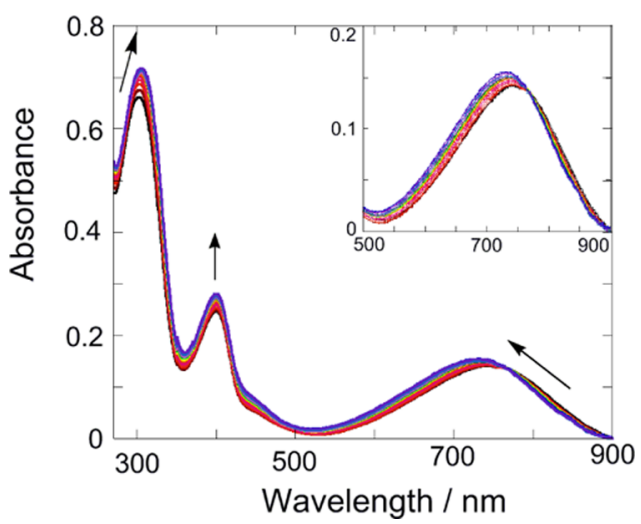

Figure 2. UV/vis spectra of compound $\mathbf{1}$ in ethyl acetate $(158 \mu \mathrm{M})$ at $0.1,20,40,60,80,100,120,140,160,180,200,220,240,260,280$, and $300 \mathrm{MPa}$, measured in a high-pressure cell at room temperature.

charge-transfer (CT) band ${ }^{15}$ (A) with full-width at halfmaximum (FWHM) of $3522 \mathrm{~cm}^{-1}$ around 500-900 nm and two absorption maxima with FWHM of $3268 \mathrm{~cm}^{-1}$ at ca. 400 $\mathrm{nm}$ (B, see below for the assignment) and of $7627 \mathrm{~cm}^{-1}$ at ca. $300 \mathrm{~nm}$ (C; see below for the assignment) were observed in ethyl acetate under an ambient pressure $(0.1 \mathrm{MPa})$ at room temperature. According to the $E_{\mathrm{T}}$ definition, ${ }^{14}$ the $E_{\mathrm{T}}$ value in ethyl acetate at $0.1 \mathrm{MPa}$ was determined to be $38.5 \mathrm{kcal} \mathrm{mol}^{-1}$ estimated from the absorption maximum of the $\mathbf{A}$ band, which is in good agreement with the literature value of $38.1 \mathrm{kcal}$ $\mathrm{mol}^{-1}$

Gradual increase of the applied pressure from 0.1 to 300 $\mathrm{MPa}$ causes a monotonic hyperchromic effect at the whole spectral range studied since effective concentrations are elevated upon pressurization. The FWHM values of the three bands do not change throughout the applied hydrostatic pressure. On the other hand, the three absorption maxima behave very differently: the $\mathbf{A}$ band showed a steady hypsochromic shift from $742 \mathrm{~nm}$ at $0.1 \mathrm{MPa}$ to $731 \mathrm{~nm}$ at $300 \mathrm{MPa}$ with increasing hydrostatic pressure in sharp contrast to a slight bathochromic shift from $302 \mathrm{~nm}$ at $0.1 \mathrm{MPa}$ to 306 $\mathrm{nm}$ at $300 \mathrm{MPa}$ for the $\mathrm{C}$ band, whereas there are almost no changes for the B band. Similar pressure-induced shifts of the three bands were also observed in other solvents (see Figures S1-S7 in the Supporting Information (SI)).

As can be seen from Figure 3, the gradual shifts in the absorption bands $\mathbf{A}$ and $\mathbf{C}$ show both good linear relationships against the pressure applied, affording slopes $(\alpha)$ of $\alpha_{\mathrm{A}}=0.80$ $\mathrm{cm}^{-1} \mathrm{MPa}^{-1}$ for the $\mathrm{A}$ band and of $\alpha_{\mathrm{C}}=-1.40 \mathrm{~cm}^{-1} \mathrm{MPa}^{-1}$ for the $\mathrm{C}$ band, respectively. These slopes observed in other solvents are summarized in Table 1 . Indicator $\mathbf{1}$ is

Table 1. Hydrostatic Pressure-Induced Spectral Changes of Reichardt's Dye in Organic Solvents Examined

\begin{tabular}{lccc}
\multicolumn{1}{c}{ solvent } & $\begin{array}{c}E_{\mathrm{T}}{ }^{a} \\
\left(\mathrm{kcal} \mathrm{mol}^{-1}\right)\end{array}$ & $\begin{array}{c}\alpha_{\mathrm{C}} \\
\left(\mathrm{cm}^{-1} \mathrm{MPa}^{-1}\right)\end{array}$ & $\begin{array}{c}\alpha_{\mathrm{A}} \\
\left(\mathrm{cm}^{-1} \mathrm{MPa}^{-1}\right)\end{array}$ \\
ethyl acetate & 38.1 & -1.40 & 0.80 \\
chloroform & 39.1 & -1.51 & 1.01 \\
dichloromethane & 40.7 & -1.64 & 1.38 \\
acetone & 42.2 & $b$ & 0.89 \\
acetonitrile & 45.6 & -0.82 & 0.87 \\
2-propanol & 48.4 & -1.10 & 1.39 \\
ethanol & 51.9 & -0.98 & 1.34 \\
methanol & 55.4 & -0.84 & 1.14
\end{tabular}

${ }^{a}$ Empirical polarity parameters of solvents by Reichardt; see ref 14 . ${ }^{b}$ Not applicable.

spectroscopically susceptible to hydrostatic pressure stimuli, as expected. The apparent $E_{\mathrm{T}}$ value at $300 \mathrm{MPa}$ in ethyl acetate is $39.2 \mathrm{kcal} \mathrm{mol}^{-1}$, which is mostly equal to the one in chloroform at $0.1 \mathrm{MPa}$, and eventually, the value in methanol at $300 \mathrm{MPa}$ reached $56.1 \mathrm{kcal} \mathrm{mol}^{-1}$, which is comparable to glycol $\left(E_{\mathrm{T}} ; 56.3 \mathrm{kcal} \mathrm{mol}^{-1}\right)$ as a more polar solvent. From the dual indicator point of view, the two sensitive bands can mutually be used as a reference; the slopes at the $\mathbf{A}$ band in (a)

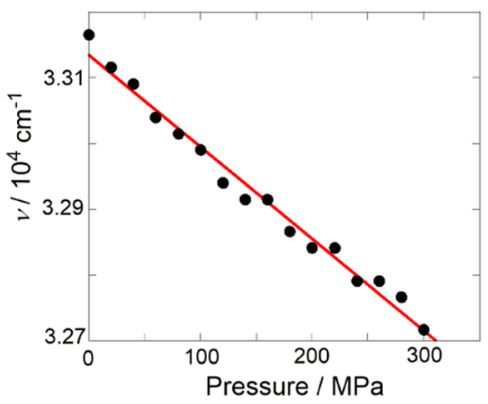

(b)

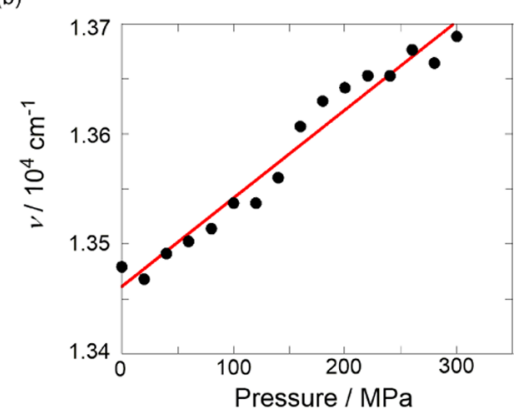

Figure 3. Plots of absorption maxima at (a) the $\mathbf{C}$ band (correlation coefficient $r=0.984$ ) and (b) the A band $(r=0.963)$ in ethyl acetate. 
dichloromethane and 2-propanol are quite similar but those at the $\mathbf{C}$ band differ remarkably.

The absorption spectrum has been simulated using TDDFT(LRC- $\omega$ PBEh), including the lowest 200 singlet states. The theoretical spectrum is shifted by $\delta \lambda=134 \mathrm{~nm}$ to guide the eye and is shown in Figure 4 (blue line). Three CT bands

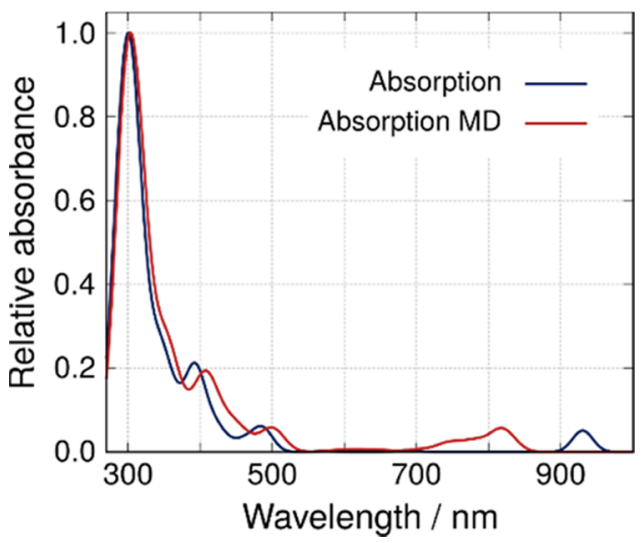

Figure 4. Theoretical absorption spectra. In blue: absorption at the ground-state minimum geometry. In red: averaged absorption over 30 snapshot geometries taken from the AIMD propagation in the ground state. A bathochromic shift of $\delta \lambda=134 \mathrm{~nm}$ has been applied to the whole spectrum to align it on the experimental one. A broadening of $\Delta=10 \mathrm{~nm}$ has been used.

are observed at 572,688 , and $930 \mathrm{~nm}$. These three bands form the experimentally observed large $\mathbf{A}$ band around $800 \mathrm{~nm}$. Both the shorter wavelength bands $\mathbf{B}$ and $\mathbf{C}$ are also reproduced at 301 and $392 \mathrm{~nm}$ and are attributed to a mix of local excitations (LE) and CT, and CT transitions, respectively.

The peak calculated at $484 \mathrm{~nm}$ corresponds to the shoulder observed around $450 \mathrm{~nm}$ experimentally. The nature of the different peaks are illustrated by the difference of density associated to the transition from the ground state to the excited states with the largest oscillator strength; see Figures 5 and S8 (SI). All absorbing states are mainly of CT character, with a small mixing with local excitation (LE) occurring for the state lying within the absorption band around $300 \mathrm{~nm}$. The average absorption spectrum calculated using 30 snapshots taken from an AIMD trajectory is shown in Figure 4 (red line). The motions in the ground state lead to a shift and a

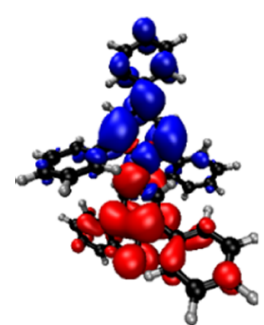

S1 $(929 \mathrm{~nm})$

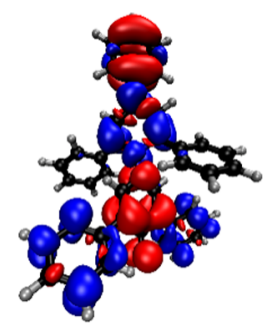

S25 $(393 \mathrm{~nm})$

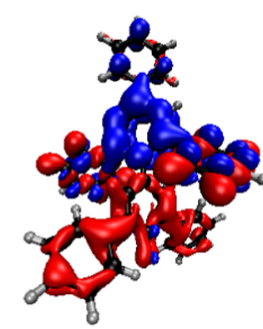

S116 (308 nm)
Figure 5. Difference of electronic densities between the states composing the main studied absorption bands and the ground state. When said band is comprised of several states, only one representative transition is shown. See Figure SI for a description of additional states. Red: loss of electronic density, blue: gain. The numbering of the state and its transition wavelength are shown below. broadening of the CT band found at $930 \mathrm{~nm}$. It spans from around 550-900 $\mathrm{nm}$ and is in good agreement with the experimentally observed band. Both peaks, at 484 and $392 \mathrm{~nm}$, are shifted by $16 \mathrm{~nm}$ toward longer wavelengths (to 500 and $408 \mathrm{~nm}$, respectively). The intense peak at $300 \mathrm{~nm}$ and the shoulder around $250 \mathrm{~nm}$ are qualitatively not affected by the ground-state molecular motions.

The geometry of the minimum of energy in the ground state of 1 corresponds to a quasi $C_{2}$ symmetry, with the $C_{2}$ axis along the $\mathrm{ON}$ bond. The values of $\tau_{i}$, defined in Figure 1 , at this geometry are reported in Table 2. $\tau_{1}\left(31.1^{\circ}\right)$ and $\tau_{2}$

Table 2. Values of the $\tau_{i}$ Angles, Their Average over the Dynamics $\left(\left\langle\tau_{i}\right\rangle\right)$ and the Variance of Their Distribution over Time $\left(\sigma_{i}\right)^{a}$

\begin{tabular}{|c|c|c|c|}
\hline$i$ & $\tau_{i}$ & $\left\langle\tau_{i}\right\rangle$ & $\sigma_{i}$ \\
\hline 1 & 31.1 & 25.0 & 20.3 \\
\hline 11 & -53.2 & -45.3 & 6.4 \\
\hline 12 & -51.0 & -47.3 & 7.3 \\
\hline 2 & -49.9 & -47.8 & 7.7 \\
\hline 21 & 35.2 & 29.7 & 8.6 \\
\hline 22 & 35.9 & 28.2 & 9.1 \\
\hline
\end{tabular}

${ }^{a}$ All values are reported in degrees.

$\left(-49.9^{\circ}\right)$ are rotations of part of the system around the $C_{2}$ axis and therefore do not break the symmetry. The four other angles can be put into two groups: $\tau_{11}$ and $\tau_{12}$ (-53.2 and -51.0 , respectively) and $\tau_{21}$ and $\tau_{22}$ (35.2 and 35.9, respectively).

The planarity of the molecule over the ground-state dynamics is investigated by looking at the $\tau$ angles along the AIMD trajectory. The distribution of the $\tau$ angles is shown in Figure 6 and the average value $\left\langle\tau_{i}\right\rangle$ and the variance $\sigma_{i}$ are reported in Table 2. Two different quasi normal distributions can be observed at $\sim-47$ and $\sim 27^{\circ}$ corresponding to two minima. Angles $\tau_{11}, \tau_{12}$, and $\tau_{2}$ are rotations around neighboring $\mathrm{C}-\mathrm{C}$ bonds. Because of the proximity of bulky groups (see Figure 1), the angles are constrained to larger values to minimize steric hindrance. $\tau_{1}, \tau_{21}$, and $\tau_{22}$ are the rotations of groups located at either end of the molecule. There, the steric hindrance is much smaller and the phenyl groups can adopt a conformation closer to planarity. With a variance of $\sigma_{1}=20.3^{\circ}, \tau_{1}$ is the most flexible angle. All the other five angles have significantly smaller variance (of about $7^{\circ}$ ) as they are constrained by steric hindrance. The two ending phenyl groups charactered by $\tau_{21}$ and $\tau_{22}$ have a slightly larger variance due to their position. These overall small variances stress out the spatial congestion and a planar conformation is unlikely even under the high-pressure conditions. This fact indicates that the spectral changes of the indicator $\mathbf{1}$ by pressurizing are highly likely not to originate from structural changes of the phenyl groups but rather from inherent changes of the solvent's physical properties, i.e., refractive index and thus polarizability under high pressure. ${ }^{16}$ The fact that the FWHM of the three experimentally observed bands do not change with the pressure points to the same conclusion as a change of the different $\tau$ angles would lead to a relative shift of the absorption energy of the electronic states depending on their nature.

The response of the energy of an electronic state to a change of polarity of its environment depends on the nature of the said state and on its dipole moment in particular. The absorption 

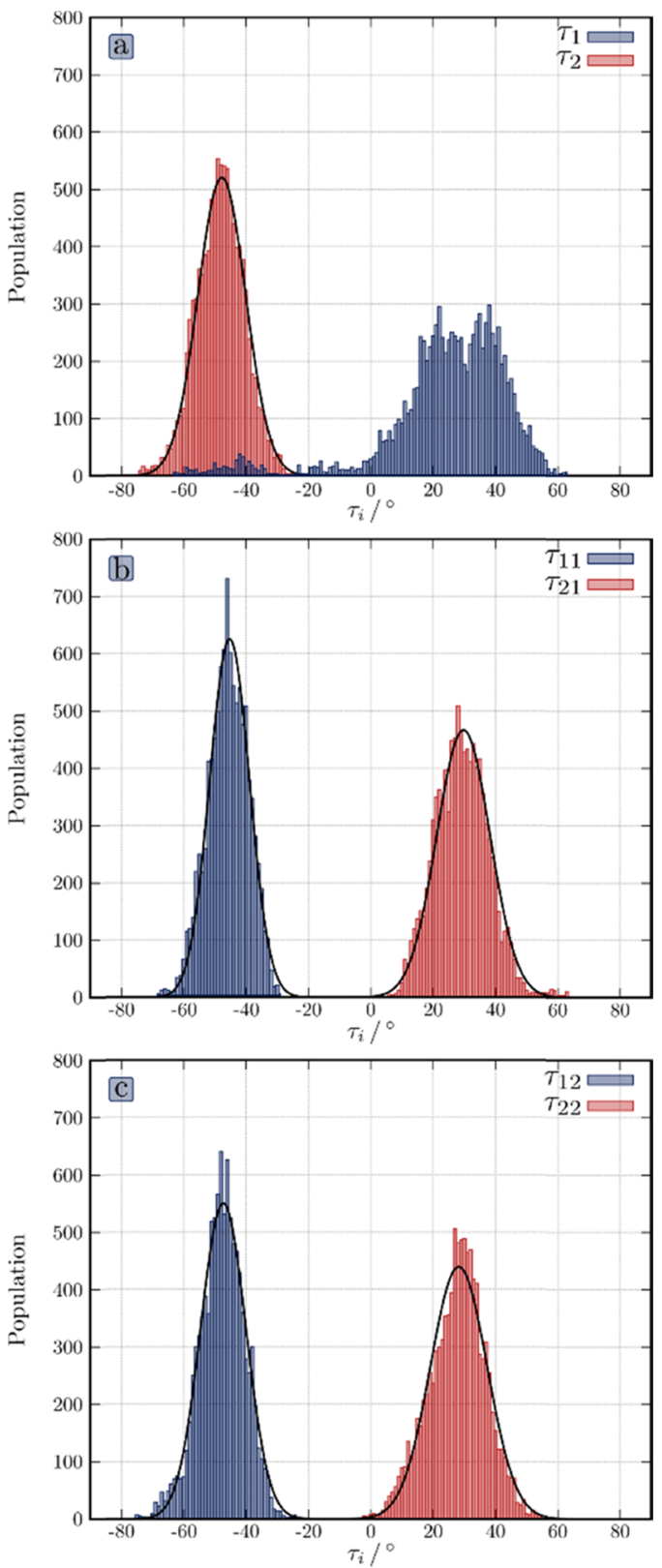

Figure 6. Distribution of the angles (a) $\tau_{1}, \tau_{2}$, (b) $\tau_{11}, \tau_{21}$, and (c) $\tau_{12}$ and $\tau_{22}$ along the AIMD propagated in the ground state. When the distribution follows a normal law $\mathrm{g}\left(\tau_{i}\right)$, this one is shown in black lines, where $g\left(\tau_{i}\right)=\frac{1}{\sigma_{i} \sqrt{2 \pi}} \mathrm{e}^{-1 / 2\left(\tau_{i}-\tau_{i} / \sigma_{i}\right)^{2}} \cdot\left\langle\tau_{i}\right\rangle$ and $\sigma_{i}$ are reported in Table 2.

energy of a transition therefore depends on the difference of the dipole moment of the excited state $\left(\vec{\mu}_{\mathrm{ES}}\right)$ and of the ground state $\left(\vec{\mu}_{\mathrm{GS}}\right)$. The electronic ground state has a dipole moment of $\vec{\mu}_{\mathrm{GS}}=15.5 \mathrm{D}$ along the $\overrightarrow{\mathrm{ON}}$ direction. At equilibrium, the solvent accommodates this dipole and an increase of polarity of the environment will further stabilize the ground state.

The first excited state $S_{1}$, composing the band $\mathbf{A}$, is a charge transfer from the "bottom" to the "top" of the molecule, i.e., in the same direction of $\vec{\mu}_{\mathrm{GS}}$. This CT induces a flip of the dipole moment in the excited state: $\vec{\mu}_{\mathrm{ES}}=4.8 \mathrm{D}$ along the $\overrightarrow{\mathrm{NO}}$ direction. The capacity of the solvent to reorganize to accommodate this large dipole moment change is hindered by the increase of pressure. This leads to an increase of the absorption energy and therefore to the hypsochromic shift of the $\mathbf{A}$ band observed experimentally.

The main electronic states composing the absorption band C have a dipole moment in the same direction as $\vec{\mu}_{\mathrm{GS}}$ but of lower intensity. The interaction of these states with the solvent is therefore weaker than the ground state interaction with the environment. Increasing the pressure brings the solvent molecule out of their equilibrium geometry and the ground state is therefore destabilized. This destabilization is not as large for the electronic excited states composing the $\mathbf{C}$ absorption band as their dipole moment, and therefore, their interaction with the solvent is smaller. This results in a decrease of the energy gap between the ground state and the states composing the $\mathbf{C}$ absorption band and therefore to a bathochromic shift of the $\mathbf{C}$ band.

Therefore, the contrasting pressure-induced wavelength shifts of the $\mathbf{A}$ and the $\mathbf{C}$ bands can be attributed to the relative stabilization of ground or excited states, respectively, as were the cases with those observed in aromatic compounds accompanied by red shifts (related to ${ }^{1} \mathrm{LE}$ transitions) upon hydrostatic pressurization. ${ }^{13 \mathrm{~m}, 17}$

\section{CONCLUSIONS}

In conclusion, we have demonstrated the spectral controls of Reichardt's dye induced by hydrostatic pressure, enabling it to be used as a colorimetric polarity/pressure dual indicator. The pressure-induced spectral changes are very contrasted at the $\mathbf{A}$ and $\mathbf{C}$ bands, the origins of which were supported by the TDDFT calculations. It can be therefore emphasized that the present approach thus observed by using Reichardt's dye may be expandable to other chromophores and/or fluorophores for developing further dual indicators.

\section{EXPERIMENTAL SECTION}

4.1. General. UV/vis spectra were recorded on JASCO V560. Spectrophotometric grade solvents and Reichardt's dye were used without further purification.

4.2. Computational Details. All calculations were performed with the long range corrected LRC- $\omega$ PBEh functional $^{18 \mathrm{a}}$ and the $6-31 \mathrm{G}^{*}$ Pople basis set ${ }^{18 \mathrm{~b}, \mathrm{c}}$ within the Qchem 5.0 package. ${ }^{18 \mathrm{~d}}$ The range separation parameter $\omega=$ $0.148 a_{0}{ }^{-1}$ was determined using the optimal tuning procedure that have proven efficient for organic molecule exhibiting low lying charge transfer states. ${ }^{18, \mathrm{f}}$ The ground state minimum geometry has been optimized with DFT and a frequency analysis has been performed to ensure there were no imaginary frequencies. The electronic structure was computed with Time Dependent DFT (TD-DFT) within the Tamm-Dancoff approximation. ${ }^{18 g}$ The absorption spectrum was both determined by TD-DFT calculations including the lowest 200 singlet states and by averaging the absorption spectra of 30 different structures taken randomly along an ab initio molecular dynamics simulation performed with TeraChem ${ }^{18 \mathrm{~h}}$ with the $3-21 \mathrm{G}^{*}$ basis set $^{18 \mathrm{i}, \mathrm{j}}$ and the PBE functional, ${ }^{18 \mathrm{k}, \mathrm{l}}$ including the DFT-D3 Grimme dispersion correction. ${ }^{18 \mathrm{~m}}$ The oscillator strength of each transition $\left(f_{n}\right)$ of energy $\omega_{n}$ was broadened with a Gaussian function

$$
g\left(\omega-\omega_{n}\right)=\sqrt{\frac{2}{\pi \Delta^{2}}} \exp \left(\frac{-2\left(\omega-\omega_{n}\right)^{2}}{\Delta^{2}}\right)
$$

where $\Delta$ is the full-width at half maximum set to $10 \mathrm{~nm}$. 
4.3. General Procedure for Measurements under Hydrostatic Pressure. UV/vis spectroscopic experiments under high pressure were performed by using the high-pressure apparatus reported previously. ${ }^{19}$ A solution of a given concentration of compound $\mathbf{1}$ was introduced to a quartz cell for high pressure $(3 \mathrm{~mm}$ width, $2 \mathrm{~mm}$ depth, and $7 \mathrm{~mm}$ height). The quartz cell was connected to a Teflon tube for adjusting the applied pressure, sealed by a metal stopper, and then placed in the high pressure apparatus. The sample solution thus put into the apparatus was measured by UV/vis spectroscopy upon hydrostatically pressurization from 0.1 to $300 \mathrm{MPa}$.

\section{ASSOCIATED CONTENT}

\section{S Supporting Information}

The Supporting Information is available free of charge at https://pubs.acs.org/doi/10.1021/acsomega.9b03880.

$\mathrm{UV} /$ vis spectra of the compound 1 under high pressure and difference of electronic associated to the most absorbing transition (PDF)

\section{AUTHOR INFORMATION}

\section{Corresponding Authors}

*E-mail: julien.eng@ncl.ac.uk (J.E).

*E-mail: gaku@chem.titech.ac.jp (G.F.).

ORCID $\odot$

Julien Eng: 0000-0002-7118-7242

Tetsuo Okada: 0000-0002-1976-7936

Yoshihisa Inoue: 0000-0001-6018-0558

Gaku Fukuhara: 0000-0002-2189-8943

\section{Notes}

The authors declare no competing financial interest.

\section{ACKNOWLEDGMENTS}

This work was supported by Grant-in-Aid for Scientific Research (B) (No. 19H02746) from JSPS and Japan Science Technology Agency (JST), PRESTO (No. JPMJPR17PA), and by the EPSRC through grants EP/N028511/1, EP/R021503/1 and EP/P012388/1, all of which are gratefully appreciated. Data supporting this publication are openly available under a "Creative Commons License." Additional meta-data are available at $10.25405 /$ data.ncl.11336633. Please contact Newcastle Research Data Service at rdm@ncl.ac.uk for access instructions.

\section{REFERENCES}

(1) (a) Wang, B.; Anslyn, E. V., Eds.; Chemosensors: Principles, Strategies, and Applications; Wiley: Hoboken, 2011. (b) Fukuhara, G. Polymer-based supramolecular sensing and application to chiral photochemistry. Polym. J. 2015, 47, 649-655. (c) Fukuhara, G. Allosteric signal-amplification sensing with polymer-based supramolecular hosts. J. Incl. Phenom. Macrocycl. Chem. 2019, 93, 127-143.

(2) (a) Tamura, Z.; Terada, R.; Ohno, K.; Maeda, M. Features of Phenolsulfonphthalein and Phenolphthalein Substituted at All OrthoPositions of Phenols with Bromine. Anal. Sci. 1999, 15, 339-342. (b) Qu, F.; Li, N. B.; Luo, H. Q. Highly Sensitive Fluorescent and Colorimetric $\mathrm{pH}$ Sensor Based on Polyethylenimine-Capped Silver Nanoclusters. Langmuir 2013, 29, 1199-1205. (c) Noh, J. Y.; Park, G. J.; Na, Y. J.; Jo, H. Y.; Lee, S. A.; Kim, C. A colorimetric "nakedeye" $\mathrm{Cu}(\mathrm{II})$ chemosensor and $\mathrm{pH}$ indicator in $100 \%$ aqueous solution. Dalton Trans. 2014, 43, 5652-5656.

(3) (a) Yeung, M. C.-L.; Yam, V. W.-W. Luminescent cation sensors: from host-guest chemistry, supramolecular chemistry to reaction- based mechanisms. Chem. Soc. Rev. 2015, 44, 4192-4202. (b) Busschaert, N.; Caltagirone, C.; Rossom, W. V.; Gale, P. A. Applications of Supramolecular Anion Recognition. Chem. Rev. 2015, $115,8038-8155$.

(4) (a) Elosua, C.; Matias, I. R.; Bariain, C.; Arregui, F. J. Volatile Organic Compound Optical Fiber Sensors: A Review. Sensors 2006, 6, 1440-1465. (b) Lee, M. Y.; Lee, H. R.; Park, C. H.; Han, S. G.; Oh, J. H. Organic Transistor-Based Chemical Sensors for Wearable Bioelectronics. Acc. Chem. Res. 2018, 51, 2829-2838.

(5) (a) Salinas, Y.; Martínez-Máñez, R.; Marcos, M. D.; Sancenón, F.; Costero, A. M.; Parra, M.; Gil, S. Optical chemosensors and reagents to detect explosives. Chem. Soc. Rev. 2012, 41, 1261-1296. (b) Schroeder, V.; Savagatrup, S.; He, M.; Lin, S.; Swager, T. M. Carbon Nanotube Chemical Sensors. Chem. Rev. 2019, 119, 599663.

(6) (a) Hembury, G. A.; Borovkov, V. V.; Inoue, Y. Chirality-Sensing Supramolecular Systems. Chem. Rev. 2008, 108, 1-73. (b) Yashima, E.; Ousaka, N.; Taura, D.; Shimomura, K.; Ikai, T.; Maeda, K. Supramolecular Helical Systems: Helical Assemblies of Small Molecules, Foldamers, and Polymers with Chiral Amplification and Their Functions. Chem. Rev. 2016, 116, 13752-13990.

(7) (a) Kubota, R.; Hamachi, I. Protein recognition using synthetic small-molecular binders toward optical protein sensing in vitro and in live cells. Chem. Soc. Rev. 2015, 44, 4454-4471. (b) Zwang, T. J.; Tse, E. C. M.; Barton, J. K. Sensing DNA through DNA Charge Transport. ACS Chem. Biol. 2018, 13, 1799-1809.

(8) (a) Andón, F. T.; Fadeel, B. Programmed Cell Death: Molecular Mechanisms and Implications for Safety Assessment of Nanomaterials. Acc. Chem. Res. 2013, 46, 733-742. (b) Vadevoo, S. M. P.; Gurung, S.; Khan, F.; Haque, M. E.; Gunassekaran, G. R.; Chi, L.; Permpoon, U.; Lee, B. Peptide-based targeted therapeutics and apoptosis imaging probes for cancer therapy. Arch. Pharm. Res. 2019, $42,150-158$.

(9) (a) Rekharsky, M. V.; Inoue, Y. Complexation Thermodynamics of Cyclodextrins. Chem. Rev. 1998, 98, 1875-1917. (b) Fukuhara, G.; Okazaki, T.; Lessi, M.; Nishijima, M.; Yang, C.; Mori, T.; Mele, A.; Bellina, F.; Chiappe, C.; Inoue, Y. Chiral ionic liquid-mediated photochirogenesis. Enantiodifferentiating photocyclodimerization of 2-anthracenecarboxylic acid. Org. Biomol. Chem. 2011, 9, 7105-7112. (10) (a) Inoue, Y.; Ikeda, H.; Kaneda, M.; Sumimura, T.; Everitt, S. R. L.; Wada, T. Entropy-Controlled Asymmetric Photochemistry: Switching of Product Chirality by Solvent. J. Am. Chem. Soc. 2000, 122, 406-407. (b) Inoue, Y.; Wada, T.; Asaoka, S.; Sato, H.; Pete, J.P. Photochirogenesis: multidimensional control of asymmetric photochemistry. Chem. Commun. 2000, 251-259.

(11) Inoue, Y.; Matsushima, E.; Wada, T. Pressure and Temperature Control of Product Chirality in Asymmetric Photochemistry. Enantiodifferentiating Photoisomerization of Cyclooctene Sensitized by Chiral Benezenepolycarboxylates. J. Am. Chem. Soc. 1998, 120, 10687-10696.

(12) (a) Weber, G.; Tanaka, F.; Okamoto, B. Y.; Drickamer, H. G. The Effect of Pressure on the Molecular Complex of Isoalloxazine and Adenine. Proc. Natl. Acad. Sci. U.S.A 1974, 71, 1264-1266. (b) Torgerson, P. M.; Drickamer, H. G.; Weber, G. Inclusion Complexes of Poly- $\beta$-cyclodextrin: A Model for Pressure Effects upon Ligand-Protein Complexes. Biochemistry 1979, 18, 3079-3083. (c) Williams, R. K. Pressure Enhancement of Charge-Trasfer Complexing of 1-Methyl-3-(carbomethoxy)pyridinium Cation and 8-Chlorotheophyllinate Anion in Aqueous Solution. J. Phys. Chem. 1981, 85, 1795-1799. (d) Letcher, T. M.; Mercer-Chalmers, J. D.; Kay, R. L. Volume changes in complex formation between crown ethers of cryptand-222 and alkali metals in various solvents. Pure Appl. Chem. 1994, 66, 419-427. (e) Isaacs, N. S.; Nichols, P. J.; Raston, C. L.; Sandova, C. A.; Young, D. J. Solution volume studies of a deep cavity inclusion complex of $\mathrm{C}_{60}$ : $\left[p\right.$-benzylcalix $[5]$ arene $\left.\subset \mathrm{C}_{60}\right]$. Chem. Commun. 1997, 1839-1840. (f) Abou-Hamdan, A.; Bugnon, P.; Saudan, C.; Lye, P. G.; Merbach, A. E. High-Pressure Studies as a Novel Approach in Determining Inclusion Mechanisms: Thermodynamics and Kinetics of the Host-Guest Interactions for $\alpha$-Cyclo- 
dextrin Complexes. J. Am. Chem. Soc. 2000, 122, 592-602. (g) Saudan, C.; Dunand, F. A.; Abou-Hamdan, A.; Bugnon, P.; Lye, P. G.; Lincoln, S. F.; Merbach, A. E. A Model for Sequential Threading of $\alpha$-Cyclodextrin onto a Guest: A Complete Thermodynamic and Kinetic Study in Water. J. Am. Chem. Soc. 2001, 123, 10290-10298. (h) Ruloff, R.; Seelbach, U. P.; Merbach, A. E.; Klärner, F.-G. Molecular tweezers as synthetic receptors: the effect of presssure and temperature on the formation of host-guest complexes. J. Phys. Org. Chem. 2002, 15, 189-196. (i) Yang, C.; Nakamura, A.; Fukuhara, G.; Origane, Y.; Mori, T.; Wada, T.; Inoue, Y. Pressure and Temperature-Controlled Enantiodifferentiating [4+4] Photocyclodimerization of 2-Anthracenecarboxylate Mediated by Secondary Faceand Skeleton-Modified $\gamma$-Cyclodextrins. J. Org. Chem. 2006, 71, 3126-3136. (j) Yang, C.; Mori, T.; Origane, Y.; Ko, Y. H.; Selvapalam, N.; Kim, K.; Inoue, Y. Highly Stereoselective Photocyclodimerization of $\alpha$-Cyclodextrin-Appended Anthracene Mediated by $\gamma$-Cyclodextrin and Cucurbit[8]uril: A Dramatic Steric Effect Operating Outside the Binding Site. J. Am. Chem. Soc. 2008, 130, 8574-8575. (k) Kosaka, T.; Iwai, S.; Fukuhara, G.; Imai, Y.; Mori, T. Hydrostatic Pressure on Toroidal Interactinon and Propeller Chirality of Hexaarylbenzens: Explicit Solvent Effects on Differential Volumes in Methylcyclohexane and Hexane. Chem. Eur. J. 2019, 25, 20112018. (1) Yonezawa, S.; Sethy, R.; Fukuhara, G.; Kawai, T.; Nakashima, T. Pressure-dependent guest binding and release on a supramolecular polymer. Chem. Commun. 2019, 55, 5793-5796.

(13) (a) Johnson, P. C.; Offen, H. W. Effect of Pressure on Pyrene Excimer Fluorescence in Toluene. J. Chem. Phys. 1972, 56, 16381642. (b) Rollinson, A. M.; Drickamer, H. G. High Pressure Study of Luminescence from Intramolecular CT Compounds. J. Chem. Phys. 1980, 73, 5981-5996. (c) Hara, K.; Arase, T.; Osugi, J. Effect of High Pressure on Intramolecular Electron-Transfer Luminescence of 9,9'Bianthryl in Different Solvents. J. Am. Chem. Soc. 1984, 106, 19681972. (d) Hara, K.; Obara, K. Effect of Pressure on the Formation of the Intramolecular Excited Complex State in 4-(9-Anthrylmethyl)N,N-dimethylaniline. Chem. Phys. Lett. 1985, 117, 96-98. (e) Hara, K.; Yano, H. High-Pressure Study on Intramolecular Excimer Formation of 1,3-Di-1-pyrenylpropane in Various Solvents. J. Am. Chem. Soc. 1988, 110, 1911-1915. (f) Rettig, W.; Gilabert, E.; Rulliére, C. Pressure Dependence of Bicimer Formation in 4Dimethylamino-4'-cyanostilbene and Model Compounds. Chem. Phys. Lett. 1994, 229, 127-133. (g) Hara, K.; Kometani, N.; Kajimoto, O. High-Pressure Studies on the Excited-State Intramolecular Charge Transfer of 4-(N,N-Dimethylamino)triphenylphosphine in Alcohols. J. Phys. Chem. 1996, 100, 14881493. (h) Ruan, K.; Tian, S.; Lange, R.; Balny, C. Pressure Effects on Tryptophan and Its Derivatives. Biochem. Biophys. Res. Commun. 2000, 269, 681-686. (i) Alamiry, M. A. H.; Benniston, A. C.; Copley, G.; Elliott, K. J.; Harriman, A.; Stewart, B.; Zhi, Y.-G. A Molecular Rotor Based on an Unhindered Boron Dipyrromethene (Bodipy) Dye. Chem. Mater. 2008, 20, 4024-4032. (j) Alamiry, M. A. H.; Bahaidarah, E.; Harriman, A.; Bura, T.; Ziessel, R. Fluorescent molecular rotors under pressure: synergistic effects of an inert polymer. RSC Adv. 2012, 2, 9851-9859. (k) Hablot, D.; Ziessel, R.; Alamiry, M. A. H.; Bahraidah, E.; Harriman, A. Nanomechanical properties of molecular-scale bridges as visualised by intramolecular electronic energy transfer. Chem. Sci. 2013, 4, 444-453. (1) Suhina, T.; Weber, B.; Carpentier, C. E.; Lorincz, K.; Schall, P.; Bonn, D.; Brouwer, A. M. Fluorescence Microscopy Visualization of Contacts Between Objects. Angew. Chem., Int. Ed. 2015, 54, 3688-3691. (m) Sagara, Y.; Tamaoki, N.; Fukuhara, G. Cyclophane-Based Fluorescence Tuning Induced by Hydrostatic Pressure Changes. ChemPhotoChem 2018, 2, 959-963. (n) Takeda, Y.; Mizuno, H.; Okada, Y.; Okazaki, M.; Minakata, S.; Penfold, T.; Fukuhara, G. Hydrostatic Pressure-Controlled Ratiometric Luminescence Responses of a Dibenzo[a,j]phenazine-Cored Mechanoluminophore. ChemPhotoChem 2019, 3, 1203-1211.

(14) Reichardt, C.; Welton, T. Solvents and Solvent Effects in Organic Chemistry; Wiley-VCH: Weinheim, 2011.
(15) Reichardt, C. Solvatochromic Dyes as Solvent Polarity Indicators. Chem. Rev. 1994, 94, 2319-2358.

(16) Takagi, T.; Teranishi, H. Refractive Index of Liquids under High Pressure. J. Chem. Eng. Data 1982, 27, 16-18.

(17) Bovey, F. A.; Yanari, S. S. Effect of Solvent Polarizality on the Ultra-Violet Spectral Shifts of Aromatic Compounds. Nature 1960, 186, 1042-1044.

(18) (a) Rohrdanz, M. A.; Martins, K. M.; Herbert, J. M. A longrange-corrected density functional that performs well for both groundstate properties and time-dependent density functional theory excitation energies, including charge-transfer excited states. J. Chem. Phys. 2009, 130, 054112-1-8. (b) Ditchfield, R.; Hehre, W. J.; Pople, J. A. Self-Consistent Molecular-Orbital Methods. IX. An Extended Gaussian-Type Basis for Molecular-Orbital Studies of Organic Molecules. J. Chem. Phys. 1971, 54, 724-728. (c) Hehre, W. J.; Ditchfield, R.; Pople, J. A. Self-Consistent Molecular Orbital Methods. XII. Further Extensions of Gaussian-Type Basis Sets for Use in Molecular Orbital Studies of Organic Molecules. J. Chem. Phys. 1972, 56, 2257-2261. (d) Shao, Y.; Gan, Z.; Epifanovsky, E.; Gilbert, A. T. B.; Wormit, M.; Kussmann, J.; Lange, A. W.; Behn, A.; Deng, J.; Feng, X.; Ghosh, D.; Goldey, M.; Horn, P. R.; Jacobson, L. D.; Kaliman, I.; Khaliullin, R. Z.; Kuś, T.; Landau, A.; Liu, J.; Proynov, E. I.; Rhee, Y. M.; Richard, R. M.; Rohrdanz, M. A.; Steele, R. P.; Sundstrom, E. J.; Woodcock, H. L.; Zimmerman, P. M.; Zuev, D.; Albrecht, B.; Alguire, E.; Austin, B.; Beran, G. J. O.; Bernard, Y. A.; Berquist, E.; Brandhorst, K.; Bravaya, K. B.; Brown, S. T.; Casanova, D.; Chang, C.-M.; Chen, Y.; Chien, S. H.; Closser, K. D.; Crittenden, D. L.; Diedenhofen, M.; DiStasio, R. A.; Do, H.; Dutoi, A. D.; Edgar, R. G.; Fatehi, S.; Fusti-Molnar, L.; Ghysels, A.; GolubevaZadorozhnaya, A.; Gomes, J.; Hanson-Heine, M. W. D.; Harbach, P. H. P.; Hauser, A. W.; Hohenstein, E. G.; Holden, Z. C.; Jagau, T.C.; Ji, H.; Kaduk, B.; Khistyaev, K.; Kim, J.; Kim, J.; King, R. A.; Klunzinger, P.; Kosenkov, D.; Kowalczyk, T.; Krauter, C. M.; Lao, K. U.; Laurent, A. D.; Lawler, K. V.; Levchenko, S. V.; Lin, C. Y.; Liu, F.; Livshits, E.; Lochan, R. C.; Luenser, A.; Manohar, P.; Manzer, S. F.; Mao, S.-P.; Mardirossian, N.; Marenich, A. V.; Maurer, S. A.; Mayhall, N. J.; Neuscamman, E.; Oana, C. M.; Olivares-Amaya, R.; O’Neill, D. P.; Parkhill, J. A.; Perrine, T. M.; Peverati, R.; Prociuk, A.; Rehn, D. R.; Rosta, E.; Russ, N. J.; Sharada, S. M.; Sharma, S.; Small, D. W.; Sodt, A.; Stein, T.; Stück, D.; Su, Y.-C.; Thom, A. J. W.; Tsuchimochi, T.; Vanovschi, V.; Vogt, L.; Vydrov, O.; Wang, T.; Watson, M. A.; Wenzel, J.; White, A.; Williams, C. F.; Yang, J.; Yeganeh, S.; Yost, S. R.; You, Z.-Q.; Zhang, I. Y.; Zhang, X.; Zhao, Y.; Brooks, B. R.; Chan, G. K. L.; Chipman, D. M.; Cramer, C. J.; Goddard, W. A.; Gordon, M. S.; Hehre, W. J.; Klamt, A.; Schaefer, H. F.; Schmidt, M. W.; Sherrill, C. D.; Truhlar, D. G.; Warshel, A.; Xu, X.; Aspuru-Guzik, A.; Baer, R.; Bell, A. T.; Besley, N. A.; Chai, J.-D.; Dreuw, A.; Dunietz, B. D.; Furlani, T. R.; Gwaltney, S. R.; Hsu, C.-P.; Jung, Y.; Kong, J.; Lambrecht, D. S.; Liang, W.; Ochsenfeld, C.; Rassolov, V. A.; Slipchenko, L. V.; Subotnik, J. E.; Van Voorhis, T.; Herbert, J. M.; Krylov, A. I.; Gill, P. M. W.; Head-Gordon, M. Advances in molecular quantum chemistry contained in the Q-Chem 4 program package. Mol. Phys. 2015, 113, 184-215. (e) Eng, J.; Laidlaw, B. A.; Penfold, T. $\mathrm{J}$. On the geometry dependence of tuned-range separated hybrid functionals. J. Comp. Chem. 2019, 40, 2191-2199. (f) Eng, J.; Hagon, J.; Penfold, T. J. D-A $\mathrm{A}_{3}$ TADF emitters: the role of the density of states for achieving faster triplet harvesting rates. J. Mater. Chem. C 2019, 7, 12942-12952. (g) Hirata, S.; Head-Gordon, M. Time-dependent density functional theory within the Tamm-Dancoff approximation. Chem. Phys. Lett. 1999, 314, 291-299. (h) Ufimtsev, I. S.; Martinez, T. J. Quantum Chemistry on Graphical Processing Units. 3. Analytical Energy Gradients, Geometry Optimization, and First Principles Molecular Dynamics. J. Chem. Theory Comput. 2009, 5, 2619-2628. (i) Perdew, J. P.; Wang, Y. Accurate and simple analytic representation of the electron-gas correlation energy. Phys. Rev. B: Condens. Matter Mater. Phys. 1992, 45, 13244-13249. (j) Perdew, J. P.; Burke, K.; Ernzerhof, M. Generalized Gradient Approximation Made Simple. Phys. Rev. Lett. 1996, 77, 3865-3868. (k) Binkley, J. S.; Pople, J. A.; Hehre, W. J. Self-consistent molecular orbital methods. 
21. Small split-valence basis sets for first-row elements. J. Am. Chem. Soc. 1980, 102, 939-947. (1) Gordon, M. S.; Binkley, J. S.; Pople, J. A.; Pietro, W. J.; Hehre, W. J. Self-consistent molecular-orbital methods. 22. Small split-valence basis sets for second-row elements. J. Am. Chem. Soc. 1982, 104, 2797-2803. (m) Grimme, S.; Antony, J.; Ehrlich, S.; Krieg, H. A consistent and accurate ab initio parametrization of density functional dispersion correction (DFT-D) for the 94 elements H-Pu. J. Chem. Phys. 2010, 132, 154104-1-19. (n) Grimme, S.; Ehrlich, S.; Goerigk, L. Effect of the damping function in dispersion corrected density functional theory. J. Comput. Chem. 2011, 32, 1456-1465.

(19) Ayitou, A. J.; Fukuhara, G.; Kumarasamy, E.; Inoue, Y.; Sivaguru, J. Enantiospecific Photochemical Transformations under Elevated Pressure. Chem. - Eur. J. 2013, 19, 4327-4334. 